\title{
Morphological characteristics of visual cells in the endemic Korean loach Kichulchoia multifasciata (Pisces; Cobitidae) by microscopy
}

\author{
J.G. Kim, J.Y. Park \\ Department of Biological Science and Institute for Biodiversity Research, College of Natural Sciences, \\ Chonbuk National University, Jeonju, Republic of Korea
}

[Received: 8 September 2016; Accepted: 6 October 2016]

\begin{abstract}
The visual cell of the retina in the Korean loach Kichulchoia multifasciata, a bottom-dwelling freshwater loach in shallow water, contains double cones and large rods. With light microscopy, the cones form a row mosaic pattern in which the partners of double cones are linearly oriented with a large rod. In a double cone or twin cone, the two members are unequal such that one cone may be longer than the other. An anatomical unit is apparent which consists of 5 rod cells and 15 double cone cells per $20 \times 20 \mu \mathrm{m}$ area. We found that the cone cells of outer segments are linked to the inner segment by so-called "calyceal process" using a scanning electron microscopy, unlike rod cells. In the transmission electron microscopy, the outer membrane shows piles of membrane discs surrounded by double membranes. (Folia Morphol 2017; 76, 2: 186-190)
\end{abstract}

Key words: retina, rods, double cones, row mosaic, cobitidae

\section{INTRODUCTION}

The Korean loach Kichulchoia multifasciata Kim, 2009 belongs to the Family Cobitidae and is an endemic Korean freshwater loach that inhabits shallow, pebbly substrates of middle and upper streams [17, 18]. They are found in streams that have moderately rapid currents, clear water, and are exposed to direct light because of limited tree cover. These fish are diurnal and mainly feed on algae on the surface of pebbles and stones on aquatic insects [18]. Most cobitid species are benthic freshwater fish with small heads and small eyes. Little is known about the visual cells in this species or any species of the family. The visual cell layer of the teleost eye is generally made up of two types of photoreceptors, rods (scotopic) and cones (phototopic), each with different light thresholds. These photoreceptors respond to changes in light intensity, which aids in schooling and feeding behaviour $[14,16,30]$. The majority of teleostomes have a duplex retina consisting of both rod cells and cone cells, but in a few shallow-water species cones are sparse or even absent (e.g. cusk-eels) and most deep-sea teleost have usually pure rod retinae [28]. Cone cells are arranged into regular, heterotypic mosaics containing 1,2 or 3 cone cells $[21,28,31$, $33,35]$. Many teleost species have unique variations on this mosaic pattern $[2,6,7]$. These variations in cone cell pattern and density may play a critical role in adaptation to feeding and photic habitats, as well as to other environmental conditions $[5,13,22,25$, $26,32]$. This present study, therefore, describes the morphology and arrangement of the visual cells in Kichulchoia multifasciata, focusing on the relation between morphology, environment and habitat.

Address for correspondence: Prof. J.Y. Park, PhD, Department of Biological Sciences, Chonbuk National University, 54896 Jeonju, Republic of Korea, tel: +82 63270 3344, fax: +82 63270 3362, e-mail: park7877@jbnu.ac.kr 

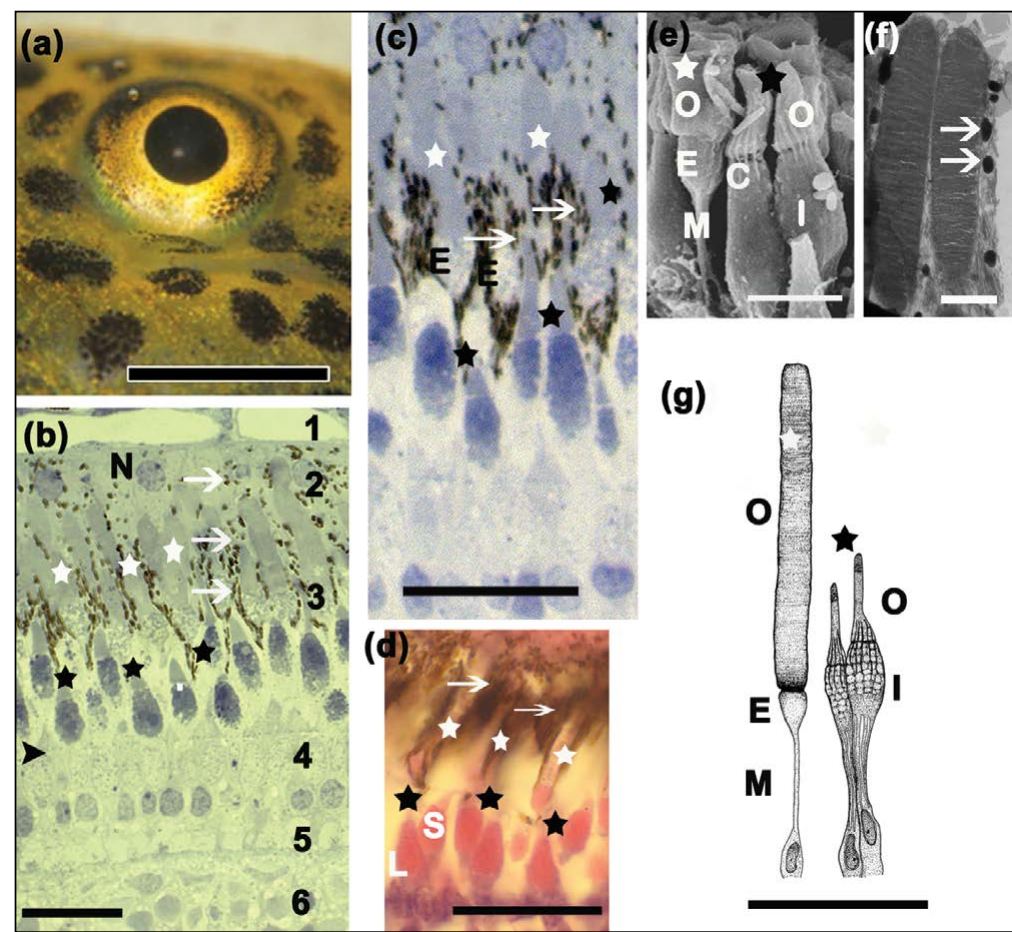

(g)

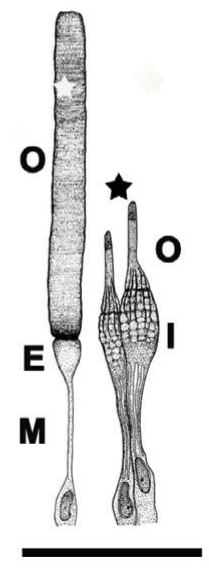

Figure 1. External morphology of the eye and gross morphology by radial sections of scleral part of the retina of $K$. multifasciata. a. Side view of the right eye; b-c. Semi-thin sections of retina stained with toluidine blue; $\mathbf{d}$. Light microscopy images of Harris haematoxylin and eosin staining. The double cone consists of big (L) and small (S) elements; e. Scanning electron microscopy image of cone and rod cell. The rod cell has no any calyceal process (C) but the cone cell apparently process. The rod's inner segment has a clear ellipsoid (E) and myoid region (M); $\mathrm{f}$. Transmission electron microscopy image of outer segment; $\mathbf{g}$. A diagram of visual cell consisting of double cones and a large rod. $\mathrm{L}$ - big element of double cone; $\mathrm{C}$ - calyceal process; $\mathrm{E}$ - ellipsoid; I - inner segment; $\mathrm{M}$ - myoid; $\mathrm{N}$ retinal pigment epithelial cell's nucleus; 0 - outer segment; $\mathrm{S}$ - small element of double cone; 1 choroid layer with capillaries; 2 - retinal pigment epithelial layer; 3 - visual cell layer; 4 - outer nuclear layer; 5 - outer plexiform layer; 6 - inner nuclear layer; arrowhead — outer limiting membrane; white arrow - pigment epithelium extensions with pigment grains; white star — rod cell; star - double cone. Bars indicate $2 \mathrm{~mm}, 20 \mu \mathrm{m}$ $20 \mu \mathrm{m}, 20 \mu \mathrm{m}, 5 \mu \mathrm{m}, 1 \mu \mathrm{m}, 10 \mu \mathrm{m}$, respectively.

\section{MATERIALS AND METHODS}

Five specimens were collected from Jusang-ri, Yoorim-myeon, Hamgang-gun, Gyeonsanam-do on the Nakdong River in Korea $\left(35^{\circ} 27 \mathrm{~N} ; 127^{\circ} 47 \mathrm{E}\right)$ during the non-spawning season. The eyes were extracted after being anaesthetized with MS-222 (200 mg/L) and fixed in $4 \%$ buffered formalin, rinsed in running water for $24 \mathrm{~h}$. Fragments were dehydrated through a standard ethanol series to $100 \%$, cleared in xylene, and embedded in wax (Paraplast, Oxford). Five-micrometre sections were deparaffinised and then stained with Harris haematoxylin and counter-stained with eosin for general histology [15]. For photographs and investigation of the eyes, Carl Zeiss Vision was used (LE REL. 4.4, Germany). For scanning electron microscopy (SEM), the fragments were prefixed in $2.5 \%$ glutaraldehyde in a $0.1 \mathrm{M}$ phosphate buffer at $\mathrm{pH}$ 7.4. Postfixation was performed in $1.0 \%$ osmium tetroxide in the same buffer. After dehydration in a graded alcohol series and drying to a critical point with liquid $\mathrm{CO}_{2}$, the dried samples were coated with gold by ion sputtering and then examined with a Hitachi S-450 SEM. For transmission electron microscopy (TEM), using the same method in fixation and dehydration as SEM, the specimens were embedded in Epon 812. They were then observed with a TEM (Hitachi-H7650; Japan). Serial semithin sections
(0.5-1.0 $\mu \mathrm{m}$ thick) were stained with toluidine blue and examined with the light microscope for gross morphology. Both radial and tangential sections were examined at right angles and parallel to the plane of the retina, respectively.

\section{RESULTS}

\section{External morphology of the eye}

Analysis of external morphology shows that this species has small eyes on a small head: the horizontal eye diameter is between $2.0 \%$ and $2.3 \%$ standard length. The eyes are transparent and are very similar in size; each is elliptical with the horizontal dimension being long in comparison to the short perpendicular length (Fig. 1a). There are no apparent eyelids.

\section{General structure of the retina}

Examination of radial sections by light microscopy reveals that the retina contains several layers. Layers from the outermost layer to the layer closest to the vitreous body include a choroid layer, a retinal pigment epithelial layer, a visual cell layer, an outer nuclear layer, an outer plexiform layer, an inner nuclear layer (Fig. 1b), an inner plexiform layer, and a ganglion cell layer (data not shown). In particular, the retinal pigment epithelium is the pigmented cell layer of pigment grains, melanin granules, extend- 
Table 1. Visual cells measurement in Kichulchoia multifasciata

\begin{tabular}{|c|c|c|c|c|c|c|c|c|}
\hline \multicolumn{3}{|c|}{ Visual cells } & \multicolumn{3}{|c|}{ Length $[\mu \mathrm{m}]$} & \multicolumn{3}{|c|}{ Diameter $[\mu \mathrm{m}]$} \\
\hline & & & $\mathbf{N}$ & Mean \pm SD & Range & $\mathbf{N}$ & Mean \pm SD & Range \\
\hline Rod & & & 30 & $53.30 \pm 2.10$ & $48.6 \sim 56.8$ & 30 & $4.30 \pm 0.60$ & $3.0 \sim 5.1$ \\
\hline \multirow[t]{2}{*}{ Cones } & Double & Big element & 30 & $21.60 \pm 2.30$ & $18.2 \sim 23.2$ & 30 & $5.50 \pm 0.10$ & $4.8 \sim 5.9$ \\
\hline & & Small element & 30 & $15.30 \pm 6.20$ & $10.1 \sim 18.3$ & 30 & $4.90 \pm 0.40$ & $4.0 \sim 6.5$ \\
\hline
\end{tabular}

$\mathrm{N}=$ number of determinations, Eye diameter $2.43 \pm 0.28 \mathrm{~mm}(2.10-2.83)$, Horizontal eye diameter is $2.0-2.3 \%$ standard length; SD - standard deviation

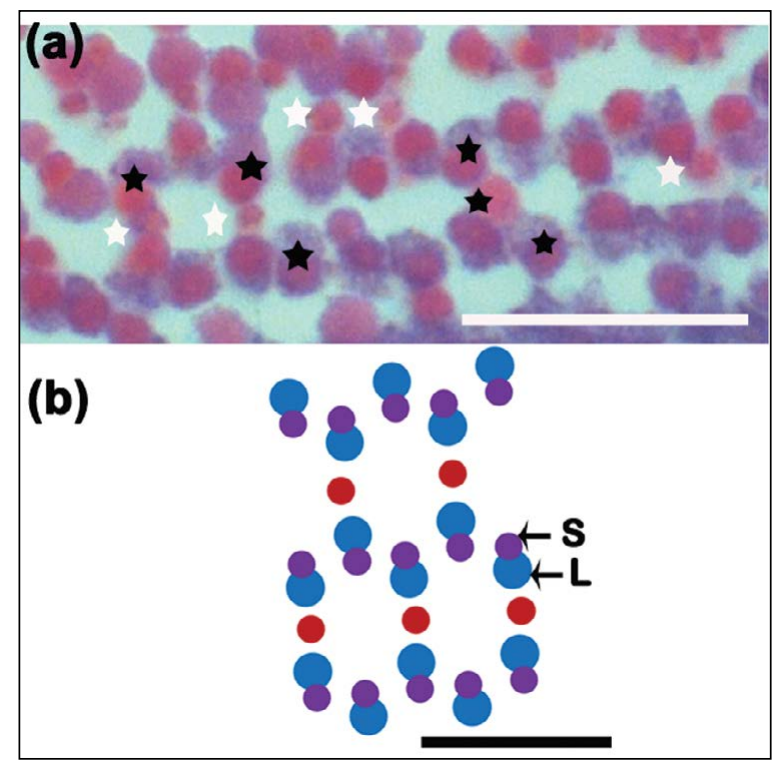

Figure 2. Tangential section through cone ellipsoids showing a row mosaic pattern in the retina of Kichulchoia multifasciata. a. Light microscopy of Harris haematoxylin and eosin staining. Double cone (star) and rod cell (white star); b. Diagram based on the left photo. The cone cells show a row mosaic pattern with double cone arranged in a row pattern along with a rod cell (red circle). The double cone has two elements, big (L) and small (S) elements. Bars indicate $50 \mu \mathrm{m}, 10 \mu \mathrm{m}$, respectively.

ing toward photoreceptor outer segments beneath a choroid layer filled with blood vessels (Fig. 1b, f).

\section{Structure of the visual cells}

The visual cell layer consists of a dense packing of both double cone cells and rods (Fig. 1b-g). The double cones are a symmetrical shape and unequal in length, with the same staining appearance. The double cones couple of two elements, big and small cones (Fig. 1b-d). The double cone cells are variable in size and they are generally shorter than the rod cells and have a thicker diameter (Table 1). In contrast to the rod cells, the outer segment is short and conical, whereas theinner segment is largeand bulbous (Fig. 1d-e).
The cell extensions reach the outer plexiform layer. Most of big elements are eosinophilic, and most small elements are haematoxylinophilic (Fig. 1d). In the semi-thin sections stained with toluidine blue, the outer segments are weakly stained but the inner segments are strong positive (Fig. $1 \mathrm{~b}-\mathrm{c}$ ). In tangential section, the double cones show a mosaic row pattern in which the contact zones between the partners of the double cones is parallel (Fig. 2a, b). The double cones do not have a homogeneous distribution because they are comprised of big and small cones. The double cones are rotated in relation to the long axis, thus forming parallel lines. The rod cells are spaced at equal distances, forming rows parallel to rows of double cones. An anatomical unit is apparent which consists of 5 rod cells and 15 double cone cells per $20 \times 20 \mu \mathrm{m}$ area. With SEM, it is apparent that the outer segments are linked to the inner segment by so-called "calyceal process" (Fig. 1e), unlike rod cells.

In the light microscope, the large rods typically have a single layer with a long and rod-shaped outer segment and a shorter inner segment (Fig. 1b-g). The outer segment is acidophilic, staining with haematoxylin, and surrounded by plenty number of pigment epithelial cells, whereas the inner segment is basophilic or eosinophilic (Fig. 1b-d). As the rods are thinner and longer cells than the cones, it is very difficult to find them through light microscope. By the semi-thin sections, however, the existence of the rod cell becomes clear (Fig. 1b, c). The outer segment is positive with toluidine blue and the ellipsoid is somewhat positive, whereas the myoid region is negative. They reach up to a mean of $53.3 \pm 2.1 \mu \mathrm{m}$ in length and $4.3 \pm 0.6 \mu \mathrm{m}$ in diameter (Table 1). With SEM, it is apparent that there is no any calyceal process between the outer segment and the inner segment, and that the inner segment consists of a separate ellipsoid and myoid region (Fig. 1e, g). In the TEM, the outer membrane shows piles of membrane discs surrounded by double membranes (Fig. 1f). 


\section{DISCUSSION}

In teleost retinal pigment epithelium (RPE), melanin pigment granules aggregate into the RPE cell body in the dark but disperse into the long apical projections in the light in response to changes in light intensity $[8,9]$. This study shows a wide range of dispersion for the melanin pigment granules, which it is extended from RPE body to the outer segments of photoreceptor cells. In many teleosts, the visual cells of the retina show a mosaic pattern, with cones being the dominating element with rods randomly interspersed $[2,20]$. Typically, the cone pattern is an arrangement of four equal, double cones surrounding a single cone $[10,23]$. This pattern may contain either central or additional single cones or both; however, in some fish, the single cone may be absent $[1,3,29]$. The cone mosaic pattern is divided into three types. In the row pattern, the double cones are parallel-oriented. In the square pattern, the double cones have an alternating, perpendicular orientation, either having an angle of $60^{\circ}$ or $90^{\circ}$. In the triangular pattern, the double cones are oriented at angles of $60^{\circ}$ and $120^{\circ}[11,12$, $20,23]$. Some investigators have suggested that the double cones are primarily sensitive to medium and long wavelengths, whereas single cones are primarily sensitive to the shorter blue wavelengths [4, 24]. Regarding the mosaic pattern, it is known that the row pattern of double cones is especially suitable for vision in dark homochromatic environments, and the square pattern has a high adaptive capacity to varying spectral distributions in luminous environments [20, 23]. These patterns occasionally show differences in some species $[5,11,13,22,25,30]$. The rod cells are varied in shape and disposition with long stout outer segments or short and thin one [28, 33].

In our study, the visual cells in the retina of $K$. multifasciata comprise large rods and small double cones, which form a row mosaic pattern in which the partners of double cones are linearly oriented with large rods. Interestingly, in a double cone or twin cone, the two members are unequal such that one cone may be longer than the other. Thus, the structure consists of big and small cones. Such double cones are thought to be formed by the fusion of single cones [10,34]. According to Nag and Bhattacharjee [27] study on the mountain-stream teleosts, two Indian loaches, Nemacheilus beavani Günther, 1868 and N. devdevi Hora, 1935, have few rods, short and long single cones and unequal double cones. Their cones show square mosaic pattern. Other hill-stream loach,
Balitora brucei Gray, 1830, has rods, double cones and single cones (short as well as long types), not showing a defined cone mosaic pattern. Nag and Bhattacharjee [27] suggested that this retinal cytoarchitecture of three loaches is present in the bottom-dwelling total insectivores and is better adapted clear water of the mountain streams having swift currents. It is also said that the row patterns of the cones, on the other hand, are present in the predominantly insectivorous forms such as giant danio Danio aequipinnatus McClelland, 1839 and Indian hill trout Barilius vagra Hamilton, 1822 that prefer to swim near the surface.

Unlike the above three loaches, however, K. multifasicata forms a row mosaic pattern in which the partners of double cones are linearly oriented with large rods. This loach is a diurnal-bottom dweller that inhabits shallow streams, mostly below $30 \mathrm{~cm}$ depth, with having moderately rapid currents and clear water, and mainly feed on algae rather than on aquatic insects [18]. In regard to the mosaic pattern, Kunz [20] suggests it is important for detection in luminous environments. However, Rossetto et al. [31] found that there is no apparent relationship between the double cone arrangement and environmental luminosity and claim instead that this pattern is well adapted to the hunting activity of predatory fish. Meanwhile, in the mountain-stream teleosts, the cone pattern development may be closely linked to ecology rather than food habits or photic environments [27].

Meanwhile, both Korean aucha perch Coreoperca herzi Herzenstein, 1896 and $K$. multifasicata of Korea are very similar in that they are typically caught at the same time and location and have a very similar habitat to each other in that they both inhabit pebbly or stony stream bottoms with moderately rapid currents where they feed on aquatic insects and small fish. Interestingly, $C$. herzi has regular mosaic pattern in which four identical double cones surround a short central single cone cell without rod cells [19].

\section{CONCLUSIONS}

Through this study, the row mosaic pattern of K. multifasciata is likely that environmental factors including microhabitats and the feeding actions play an important role in the cone pattern. With regard to the visual cells of this species, it is likely to be possible to provide clues to why they species prefers moderately rapid currents and clear water, and mainly feed on algae rather than on aquatic insects. 


\section{REFERENCES}

1. Anctil M. Structure de la rétine chez quelques téléostéens marins du plateau continental. J Fish Res Board Ca. 1969; 26(3): 597-628, doi: 10.1139/f69-055.

2. Ali MA, Anctil M. Retinas of fishes: an atlas. SpringerVerlag, New York 1976: http://dx.doi.org/10.1007/9783-642-66435-9.

3. Boehlert GW. Retinal development in postlarval through juvenile Sebastes diploproa: adaptations to a changing photic environment. Rev Can Biol. 1979; 38: 265-280.

4. Bowmaker JK. The visual pigments of fish. Prog Retin and Eye Res. 1995; 15(1): 1-31, doi: 10.1016/13509462(95)00001-1.

5. Collins BA, MacNichol EF. Triple cones found in retinas of 3 fish species. Experientia. 1979; 35(1): 106-108, doi: 10.1007/bf01917906.

6. Collin SP. A web-based archive for topographic maps of retinal cell distribution in vertebrates. Clin Exp Optom. 2008; 91(1): 85-95, doi: 10.1111/j.1444-0938.2007.00228.x, indexed in Pubmed: 18045254.

7. Collin SP, Shand J. Retinal sampling and the visual field in fish. In: Collin SP, Marshall NJ (ed.). Sensory processing in aquatic environments. Springer-Verlag, New York 2013: 139-169.

8. Dearry A, Burnside B. Dopaminergic Regulation of Cone Retinomotor Movement in Isolated Teleost Retinas: I. Induction of Cone Contraction Is Mediated by D2 Receptors. J Neurochem. 1986; 46(4): 1006-1021, doi: 10.1111/ j.1471-4159.1986.tb00612.x.

9. Dearry A, Burnside B. Stimulation of Distinct D2 Dopaminergic and ? 2 -Adrenergic Receptors Induces LightAdaptive Pigment Dispersion in Teleost Retinal Pigment Epithelium . J Neurochemi. 1988; 51(5): 1516-1523, doi: 10.1111/j.1471-4159.1988.tb01120.x.

10. Engström K. Cone types and cone arrangements in teleost retinae. Acta Zoologica. 1963; 44(1-2): 179-243, doi: 10.1111/j.1463-6395.1963.tb00408.x.

11. Fernald RD. Cone mosaic in a teleost retina: No difference between light and dark adapted states. Experientia. 1982; 38(11): 1337-1339, doi: 10.1007/bf01954937.

12. Fernald RD. Aquatic adaptations of fish eyes. In: Atema J, Fay RR, Popper AN, Tavolga WN (ed.). Sensory biology of aquatic animals. Springer-Verlag, New York 1988: 435-485.

13. Reckel F, Melzer R, Smola U. Outer retinal fine structure of the garfish Belone belone (L.) (Belonidae, Teleostei) during light and dark adaptation - photoreceptors, cone patterns and densities. Acta Zoologica. 2002; 82(2): 89-105, doi: 10.1046/j.1463-6395.2001.00071.x.

14. George CK, Robert KC. Comparative anatomy of vertebrates. McGraw Hill, Boston 2001: 387-454.

15. Gurr E. A practical manual of medical and biological staining techniques. Interscience Publishers, New York 1956: 1-99.

16. Hagedorn M, Mack A, Evans B, et al. The embryogenesis of rod photoreceptors in the teleost fish retina, Haplochromis burtoni. Dev Brain Res. 1998; 108(1-2): 217-227, doi: 10.1016/s0165-3806(98)00051-0.

17. Kim ISA. A review of the spined loaches, Family Cobitidae (Cypriniformes) in Korea. Korean J Ichthyol. 2009; 21: 7-28.
18. Kim IS, Park JY. Freshwater fishes of Korea. Kyo-Hak Publishing Co.Ltd, Seoul. 2002: 230-233.

19. Kim JG, Park JY, Kim CH. Visual cells in the retina of the aucha perchCoreoperca herziHerzenstein, 1896 (Pisces; Centropomidae) of Korea. J Applied Ichthyol. 2013; 30(1): 172-174, doi: 10.1111/jai.12311.

20. Kunz Y. Cone mosaics in a teleost retina: Changes during light and dark adaptation. Experientia. 1980; 36(12): 1371-1374, doi: 10.1007/bf01960104.

21. Lyall AH. Occurrence of triple and quadruple cones in the retina of the minnow (phoxinus laevis). Nature. 1956; 177(4519): 1086-1087, doi: 10.1038/1771086a0.

22. Lyall AH. Cone arrangements in teleost retinae. J Cell Sci. 1957; 98: 189-201.

23. Meer van der HJ. Constructional morphology of photoreceptor patterns in percomorph fish. Acta Biotheoretica. 1992; 40(1): 51-85, doi: 10.1007/bf00046551.

24. Meer van der HJ, Bowmaker JK. Interspecific variation of photoreceptors in four co-existing haplochromine cichlid fishes. Brain, Behavior Evolut. 2008; 45(4): 232-240, doi: 10.1159/000113552.

25. Monica RL. Morphology of the eye and visual acuities in the settlement-intervals of some coral reef fishes (Labridae, Scaridae). Environ Biol Fish. 2001; 62: 365-378, doi: 10.1023/A:1012214229164.

26. Nag T, Bhattacharjee J. Retinal vascularisation in the loach Noemacheilus rupicola rupicola: coexistence of falciform process and vitreal vessels. Environmental Biol Fish. 1993; 36(4): 385-388, doi: 10.1007/bf00012417.

27. Nag T, Bhattacharjee J. Retinal cytoarchitecture in some mountain-stream teleosts of India. Environ Biol Fish. 2002; 63(4): 435-449, doi: 10.1023/A:1014982218347.

28. Nicol JAC. The eyes of fishes. Clarendon Press, Oxford 1989: 308.

29. O'Connel CP. The structure of the eye of sardinops caerulea, engraulis mordax, and four other pelagic marine teleosts. J Morphol. 1963; 113: 287-329, doi: 10.1002/ jmor.1051130214, indexed in Pubmed: 14062000.

30. Polyak S. The vertebrate visual system. University of Chicago Press, Chicago 1957: 178.

31. Rossetto ES, Dolder H, Sazima I. Double cone mosaic pattern in the retina of larval and adult piranha,Serrasalmus spilopleura. Experientia. 1992; 48(6): 597-599, doi: 10.1007/bf01920245.

32. Thomas JL, Craig WH. cular dimensions and cone photoreceptor topography in adult Nile tilapia Oreochromis niloticus. Environ Biol Fish. 2010: 369-376, doi: 10.1007/ s10641-010-9652-7.

33. Wagner HJ. Retinal structure of fishes. In: Douglas RH, Djamgoz MBA (ed.). The visual system of fish. Chapman and Hall, London 1990: 109-158.

34. Wheeler TG. Color vision and retinal chromatic information processing in teleost: a review. Brain Res. 1982; 257(2): 177-235, doi: 10.1016/0165-0173(82)90017-0, indexed in Pubmed: 7049328.

35. Yuko T, Tadashi O, Fumio T. Three-Dimensional reconstitution of cone arrangement on the spherical surface of the retina in the medaka eyes. Zoological Science. 1997; 14(5): 795-801, doi: 10.2108/zsj.14.795. 